Letters to the Editor

\title{
Silver Selectivity of Novel Bis-Xanthate Derivative Containing a Diethylthionyl Group in Solvent Extraction
}

\author{
Concepcion S. Mendoza and Satsuo Kamata ${ }^{\dagger}$ \\ Department of Applied Chemistry and Chemical Engineering, Faculty of Engineering, \\ Kagoshima University, Korimoto, Kagoshima 890, Japan
}

Keywords Silver ion, bis(diethylthionylxanthato)propane, solvent extraction

Extraction with compounds containing sulfur donors are known to be selective for transistion metals in their low valence, such as copper(I), silver(I), platinum(II), or palladium(II), because of the so-called soft-soft interaction. ${ }^{1-4}$

Simple xanthates have found limited use in solvent extraction or other analytical processes, in spite of their extensive coordination, due to the fact that the xanthate anion forms rather unselective and insoluble inner complexes with most coordinating metal ions. ${ }^{5}$ The idea of neutralizing the xanthate function by the introduction of an alkylene chain to join the two xanthate groups, $\mathrm{RO}-\mathrm{C}(\mathrm{S}) \mathrm{S}^{-}$, would enhance the selectivity of the sulfur atom towards complexation with metal ions. ${ }^{6}$ Variation of the alkylene chain in the new bis-molecule is expected to provide an extra dimension in the flexibility of the reagents in the fulfillment of the coordination requirements of specific metal ions. On this point of view, the incorporation of a diethylthionyl moiety into the derivative of a bis(xanthato)alkane would lead to a novel silver-selective reagent.

\section{Experimental}

\section{Reagents}

The reaction of (2-thioethyl)alcohol with carbon disulfide in potassium hydroxide produced potassium ethylthionylxanthate. Further reaction of the xanthate with dibromopropane at $40^{\circ} \mathrm{C}$ for about $2-3 \mathrm{~h}$ of vigorous stirring afforded the bis(diethylthionylxanthato)propane as the main organic product. This is abbreviated in this communication as BdETXP and is shown in Fig. 1. The crude product was extracted with diethylether and purified by column chromatography using silica-gel, 9:1 benzene-ether eluent. The compound was identified using ${ }^{1} \mathrm{H}-\mathrm{NMR}$ and elemental analysis. The results of the analyses and some physical properties are as follows.

$\dagger$ To whom correspondence should be addressed.

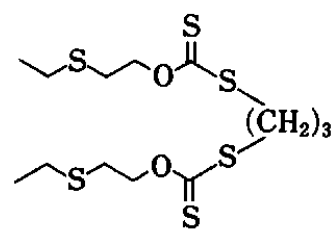

Fig. 1 General structure of BdETXP.

BdETXP: yellowish liquid; bp $>100^{\circ} \mathrm{C} ;{ }^{1} \mathrm{H}-\mathrm{NMR}$ $\left(\mathrm{CDCl}_{3}\right) \delta, \mathrm{ppm}=1.29\left(\mathrm{t}, 6 \mathrm{H}, \mathrm{CH}_{3}-\right) ; 2.14(\mathrm{q}, 4 \mathrm{H}$, $\left.-\mathrm{CH}_{2-}\right) ; 2.67$ (q, 4H, $\left.-\mathrm{CH}_{2-}\right) ; 2.83$ (q, 4H, $-\mathrm{CH}_{2-}$ ); 3.17 (m, 4H, $\left.-\mathrm{CH}_{2}-\right)$; $4.75\left(\mathrm{t}, 4 \mathrm{H},-\mathrm{CH}_{2}-\right.$ ). Found: $\mathrm{C}, 41.67$; H, 6.51\%. Calculated: C, 41.63; H, 6.52\%.

Silver stock solution, $1 \mathrm{mg} / \mathrm{ml}$, was prepared by dissolving $1.5748 \mathrm{~g} \mathrm{AgNO}_{3}$ in water and diluting to 11 . Other working solutions for the other metal ions were prepared by dissolving their nitrate or chloride salts in water. The diluent, 1,2-dichloroethane (DCE), was saturated with water before use. All reagents were of analytical grade. Distilled and deionized water is used throughout the experiments.

\section{Procedures}

An aqueous solution $(10 \mathrm{ml})$ containing the metal salt or any other reagent required was shaken at a speed of 300 oscillations $/ \mathrm{min}$ with a solution $(10 \mathrm{ml})$ of BdETXP in DCE in a $50-\mathrm{ml}$ glass stoppered cylindrical tube at $25^{\circ} \mathrm{C}$ for $1 \mathrm{~h}$. After phase separation, the metal concentrations in the aqueous phase were measured spectrophotometrically. Metal concentrations in the organic phase were calculated by mass balance of the metal content in the aqueous phase before and after equilibration.

The back-extraction experiments were performed as follows: an aliquot $(10 \mathrm{ml})$ from the separated organic solution was shaken with an aqueous stripping solution $(10 \mathrm{ml})$ at $25^{\circ} \mathrm{C}$, and the metal ion in the aqueous solution was measured again spectrophotometrically. 


\section{Results and Discussion}

The extractabilities of bis(diethylthionylxanthato)propane towards different metal ions are tabulated in Table 1. BdETXP showed high extraction selectivity for $\mathrm{Ag}^{+}$over the commonly mentioned alkali and alkaline-earth metals. The formation of a stable 6membered chelate ring $^{7-9}$ and the optimum $\mathrm{Ag}^{+}-\mathrm{S}$ distance might be responsible for the maximum extractability of the metal ion. Table 1 indicates the probability that the bis(diethylthionylxanthato)propane under study are good reagents for $\mathrm{Ag}^{+}$extraction. And it can be assumed that the extraction of $\mathrm{Ag}^{+}$through coordination by the thioether group in the bis(xanthato)alkane molecule is preferred, since the coordinating abilities of the various types of sulfur donors decrease in the order: $\mathrm{RS}^{-}>\mathrm{R}_{2} \mathrm{~S}>\mathrm{RC}=\mathrm{S} \gg$ ring sulfur. ${ }^{6}$ An enhanced $\mathrm{Ag}^{+}$extraction arises from coordination with the sulfur atoms in the alkyl chain.

In order to discuss the binding capacity of the ligands with $\mathrm{Ag}^{+}$from a quantitative view, the metal-ligand stoichiometry maintained in the extraction of $\mathrm{Ag}^{+}$from perchlorate medium has been determined. In the slope ratio method, $\log D v s . \log [\mathrm{L}]$ plot for BdETXP; where $D$ shows the distribution ratio and [L] is the ligand concentration, as shown on Fig. 2, yielded a straight line with a slope ratio value roughly equal to 1 . This means that a $1: 1 \mathrm{Ag}:$ BdETXP complex is formed, because this ligand is so flexible that the tetrahedral silver ion can be encircled and coordinated through the four thioether groups of one molecule of the ligand, giving rise to strong bonding and proximity of the silver-ligand complex. The proposed structure of the Ag-BdETXP complex using the CPK model is illustrated in Fig. 3. A stable 6membered chelate ring is formed. This assumption is similar to that for the extraction of silver with acyclic tetrathioether. ${ }^{10}$ The presence of the sulfur atom in the alkyl chain of the xanthate portion enhanced the $\mathrm{Ag}^{+}$ extraction. It may also increase the hydrophilicity of the ligand ${ }^{11}$, thereby contributing to a better efficiency of the extraction from an aqueous phase. The presence of thiocarbonyl groups prevent a linear arrangement of the ligand molecule. The direct coordination of the etheroxygen atom is excluded because of the affinity of the sulfur donor for silver and its coordination saturation. The preference of sulfur over oxygen can be attributed to the presence of a considerably covalent character in the $\mathrm{Ag}^{+}-\mathrm{S}$ bonds. ${ }^{8}$ Nevertheless, the presence of oxygen will affect the mode of coordination and hence the selectivity of the reagents.

The silver in the organic phase must be stripped to a suitable salt solution from which silver is readily recovered by electrolysis. The back-extraction of $\mathrm{Ag}^{+}$ from the organic phase was possible with $5 \mathrm{M} \mathrm{HCl}$ and with $5 \%$ thiourea solutions, both giving $100 \%$ efficiency after $1 \mathrm{~h}$ shaking time. A $5 \mathrm{M} \mathrm{HCl}$ solution is a better back-extractant than 5\% thiourea solution, because of the instability of thiourea solutions upon storage.
Table 1 Extraction of metal ions with BdETXP

\begin{tabular}{ccc}
\hline Element & Extraction, \% & $\mathrm{RSD}, \%$ \\
\hline $\mathrm{Ag}^{+}$ & 99.2 & 0.1 \\
$\mathrm{Metal}$ ions with no extraction: \\
$\mathrm{Cd}^{2+}, \mathrm{Co}^{2+}, \mathrm{Cr}^{3+}, \mathrm{Cu}^{2+}, \mathrm{Fe}^{3+}, \mathrm{Mn}^{2+}, \mathrm{Ni}^{2+}, \mathrm{Sn}^{2+}, \mathrm{Pb}^{2+}$, \\
$\mathrm{Pt}^{4+}, \mathrm{Zn}^{2+}$
\end{tabular}

$\left[\mathrm{M}^{n+}\right]=1 \times 10^{-4} \mathrm{M}$ each of the mentioned metal individually prepared in $0.1 \mathrm{M} \mathrm{NaClO}_{4},[\mathrm{BdETXP}]=2.5 \times 10^{-3} \mathrm{M}$ in DCE, shaking time $=1 \mathrm{~h}$, phase ratio $=1$.

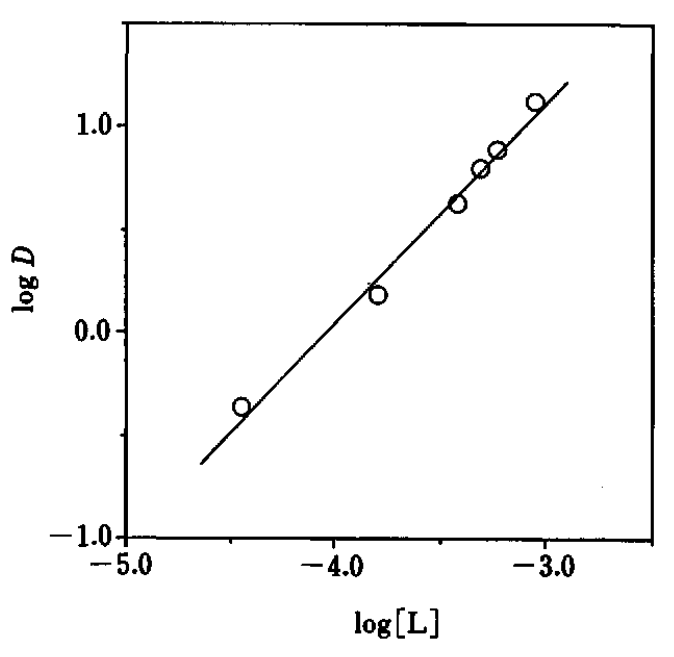

Fig. 2 Determination of the $\mathrm{Ag}^{+}-\mathrm{BdETXP}$ complex stoichiometry using the slope ratio method. Slope ratio $=0.96$. Extraction conditions: [BdETXP] $=1.0 \times 10^{-4}$ to $5 \times 10^{-3} \mathrm{M}$ in $\mathrm{DCE},\left[\mathrm{Ag}^{+}\right]=1.0 \times 10^{-4} \mathrm{M}$ in $0.1 \mathrm{M} \mathrm{NaClO}$, shaking time= $8 \mathrm{~h}$, phase ratio $=1$.

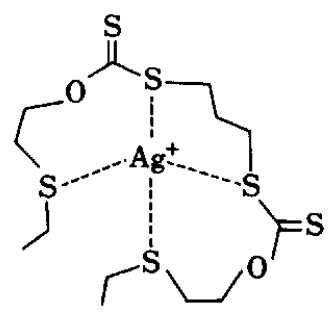

Fig. 3 Schematic representation of possible configuration of the Ag-BdETXP complex.

The BdETXP compound is a good extractant for silver ion recovery.

\section{References}

1. T. H. Handley and J. A. Dean, Anal. Chem., 33, 1087 (1961). 
2. T. V. Healy, C. J. Barton and I. Windeatt, J. Inorg. Nucl. Chem., 36, 2575 (1974).

3. T. V. Healy and C. J. Barton, J. Inorg. Nucl. Chem., 36, 2578 (1974).

4. M. Mojski, Talanta, 27, 7 (1980).

5. S. R. Rao, "Xanthates and Related Compounds", Marcel Dekker, New York, 1971.

6. M. Akbar Ali and S. E. Livingstone, Coord. Chem. Rev., 13, 101 (1974).

7. C. S. Mendoza, D. A. Chowdhury and S. Kamata, Anal. Sci., 2, 271 (1995).
8. F. Basolo and R. C. Johnson, "Coordination Chemistry", p. 130, W. A. Benjamin Inc., New York, 1964.

9. D. A. Chowdhury, C. S. Mendoza and S. Kamata, Solvent Extr. Ion Exch., 12, 1051 (1994).

10. K. Chayama and E. Sekido, Anal. Sci., 6, 883 (1990).

11. A. P. Paiva and M. Lemaire, Sep. Sci. Technol., 28, 2279 (1993).

(Received March 15, 1996)

(Accepted April 18, 1996) 